\title{
Research into the Improvement on Hexagonal Socket by Applying the System Innovation Theory
}

\author{
Ying-Hsiang Lin ${ }^{1}$, Shang-Pin Li ${ }^{2, *}$, Chien-Yu Lu3 ${ }^{3}$, Ruey-Gwo Chung ${ }^{4}$, Der-Fa Chen ${ }^{5}$ \\ ${ }^{1}$ Department of Industrial Education and Technology, National Changhua University of Education, Changhua, Taiwan, R.O.C \\ ${ }^{2}$ Department of Industrial Education and Technology, National Changhua University of Education, Changhua, Taiwan, R.O.C \\ ${ }^{3}$ Department of Industrial Education and Technology, National Changhua University of Education, Changhua, Taiwan, R.O.C \\ ${ }^{4}$ Hsiuping University of Science and Technology, Taichung, Taiwan, R.O.C \\ ${ }^{5}$ Department of Industrial Education and Technology, National Changhua University of Education, Changhua, Taiwan, R.O.C \\ ${ }^{*}$ Corresponding author
}

\begin{abstract}
A socket is used as a handling tool after matching with a ratchet wrench. Its main function is to handle all kinds of screws and nuts and other fastening parts, but sockets are often lost after falling down on the ground or rolling over before and after their use. This research employs TRIZ to improve the socket design. First, this research collects and analyzes literature related to socket design. Second, it then utilizes a contradiction matrix, 39 engineering parameters, and 40 invention principles in TRIZ to find the places that need to be improved and subsequently improves them. Lastly, this research changes the socket structure to reduce losses caused by falling down and rolling over.
\end{abstract}

Keywords- TRIZ; contradiction matrix; hexagonal socket

\section{INTRODUCTION}

A wrench is a kind of tool mainly used for locking bolts and nuts and can be roughly divided into two types in accordance with the different wrench structures: manual screw wrench and socket wrench. A manual screw wrench fastens nuts of different types through the change in the distance between two nut jaws on the wrench by rotating a screw on the head of the wrench. A socket wrench can fasten or loosen nuts and bolts by putting the sockets (as shown in Figure 1) on the nuts of corresponding type.
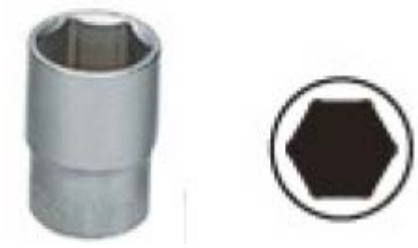

FIGURE I.

HEXAGONAL SOCKET

The Theory of Innovative (Inventive) Problem Solving is referred to as TRIZ [5]. The Theory of TRIZ was proposed in 1946 by G. S. Altshuller, a former Soviet Union inventor, who is also regarded as the father of TRIZ. Altshuller started to lead the research institutes of former Soviet Union universities and enterprises to form TRIZ research groups starting in 1946. They analyzed nearly 2.5 million pieces of global high-level invention patents and put forward the basic theory on the problem of inventions based on dialectical materialism and systematic thoughts. Currently, many scholars have been devoted to the research of TRIZ, such as Chang and Lin (2013) and Chang et al. (2015). This present research uses the contradiction matrix, 39 engineering parameters, and 40 invention principles in the Theory of Inventive Problem Solving (TRIZ) to find out the points that need improvement and then improve them.

\section{RESEARCH METHOD}

\section{A. Research Process}

As shown in Figure 2, after identifying the issues of an object, we need to find out the issues and the technical contradictions. After learning the technical contradictions, we then can develop the $39 \times 39$ contradiction matrix in search of the 40 inventive principles that can possibly solve the technical contradiction. Next, the feasible 40 inventive thinking solutions and logic thinking are employed to consider the listed programs and select the most appropriate solution to solve the problem.

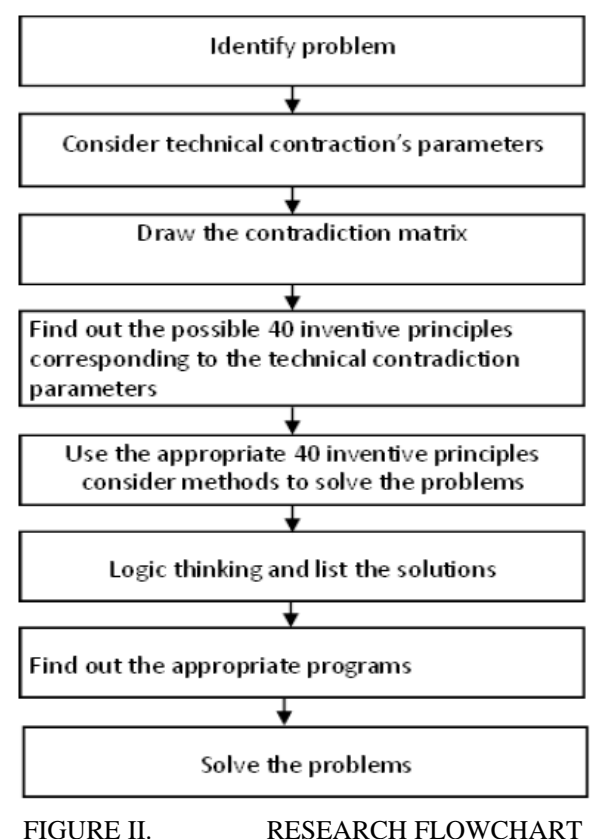




\section{B. Contradiction Matrix}

Altshuller observed each technical contradiction and developed a system accordingly. The first system regarding innovation and invention is known as the contradiction matrix. When studying patents, he would confirm and summed up the technical contradictions and the applied innovative inventive principles for this patent. Based on the summaries of a large number of patents, he summed up 39 engineering parameters and 40 innovative inventive principles, and developed the $39 \times 39$ matrix , which is a matrix using $\mathrm{i}$ to represent the improved characteristic and $\mathrm{j}$ to represent the avoidance of worsening result. Each box grid represents a type of inventive problems, and each inventive problem has corresponding $i$ and $\mathrm{j}$ coordinates. In the box grid of specific $\mathrm{i}$ and $\mathrm{j}$, there are identification codes of inventive principles to solve the problems [6].

\section{40 Inventive Principles}

40 principles provide TRIZ users a way of thinking from principle to application. Each inventive principle is a simple basic concept, and the derived thoughts from the principle can cover a wide range. Different principles' layers and details can produce different architectures and contents. Each principle and thought can empower the innovator with new answers, "think about each principle and then find out the answer" [3],[4].

\section{TECHNICAL CONTRADICTIONS OF THE NEW HEXAGONAL SOCKET}

A socket is used as a handling tool after matching with a ratchet wrench. Its main function is to handle all kinds of screws and nuts and other fastening parts, but sockets are often lost after falling down on the ground or rolling over before and after their use. Technical contradiction of hexagonal socket lies in "Speed" and "Appearance".

\section{A. Formulation of the Contradiction Matrix}

As shown in Table 1, proper i (improved characteristics) and proper $\mathrm{j}$ (results of avoiding deterioration) are found from the matrix. "Speed" in Column 9 corresponds to "Shape" in Row 17. The frames of the intersection of columns and rows represent the suggested principles that can solve the current contradiction.

TABLE I. CONTRADICTION MATRIX

\begin{tabular}{|c|c|c|c|c|c|c|}
\hline \multicolumn{2}{|c|}{$\begin{array}{l}\text { The avoidance of } \\
\text { wersening result }(\mathrm{j})\end{array}$} & 1 & $\ldots$ & 9 & .. & 39 \\
\hline \multicolumn{2}{|c|}{$\begin{array}{l}\text { Improved } \\
\text { characteristic(i) }\end{array}$} & $\begin{array}{l}\text { Weight of } \\
\text { the moving } \\
\text { object }\end{array}$ & $\cdot$ & Speed & $\begin{array}{l}\cdot \\
\cdot \\
\cdot\end{array}$ & productivity \\
\hline 1 & $\begin{array}{l}\text { Weight of the } \\
\text { moving object }\end{array}$ & & & & & \\
\hline.. & .. & & & & & \\
\hline 17 & Shape & & & $\begin{array}{l}15,18, \\
34,35\end{array}$ & & \\
\hline.. &.. & & & & & \\
\hline 39 & Productivity & & & & & \\
\hline
\end{tabular}

It can be found from the matrix that, among the 40 Invention Principles, No. 15 principle "Dynamics" and No. 35 principle "Change of Parameters" can be applied, which shall be the best suggestion for the improvement of the current technology.

The contents of No. 15 principle "Dynamics" are as follows.

1) Change characteristics of object or system under different conditions so as to achieve the best effect.

2) Segment object to be mutually moving components.

3) If the object or system cannot move, then make it move or exchange.

4) Increase degrees of freedom.

The principle can make the hexagonal socket present a smooth appearance when it executes the handling action so as to avoid injuring hands during rotation at high speed.

The contents of No. 35 principle "Change of Parameters" are as follows.

1) Change physical state.

2) Change concentration or density.

3) Change the degree of elasticity.

4). Change the temperature.

5) Change pressure.

6) Change length and volume.

7) Change other parameters.

This principle changes the length of a single direction so as to make it not roll over when the original hexagonal socket is round in appearance, but it will roll over due to its appearance after it falls down on the ground.

\section{B. Thinking and Improvement}

At the beginning, this research explored the issue from the perspective of No. 35 principle "Change of Parameters". What we need to do first is to suppose why a socket will go missing after falling down on the ground. The main reason is that its appearance is round, and that the potential energy is transformed into kinetic energy, causing it to roll after it falls down on the ground. Thus, it is not easy to get the socket back when it rolls into a crack. Next, from the perspective of No. 15 principle "Dynamics", a socket may be rotated at high speed if electric tools are used when the socket is fastening and loosening something. Users will hold an electric tool in one hand and hold the nut in the other hand during handling, and the socket will rotate at a high speed when the electric tool is started up. If the appearance of the socket is not round, but has corners, then it could easily injure hands. After summarizing the two points mentioned above, this research will change the appearance of the socket from a round shape to an elliptical shape via a change of single direction (as shown in Figure 3 New Hexagonal Socket). 


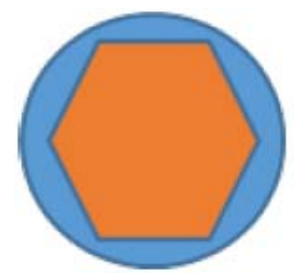

FIGURE III.

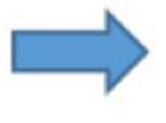

NEW HEXAGONAL SOCKET

\section{Summary}

A hexagon socket is one of the more widely used electric tools currently. This research changes the shape of a socket from round to elliptical, which will reduce the distance of rolling around on the ground after it falls down. Moreover, despite not being round in original appearance, its new elliptical appearance is still smooth and also reduces the chances of users being injured during handling.

\section{CONCLUSIONS}

TRIZ innovation theory can be applied in a lot of things, not just only products but also service. Regardless of what the industry, problems will arise inevitably. The understanding and learning of TRIZ is like the opening of an extra window, and you can have a wider vision than others. It can guide us to quickly find where the problem lies, to analyze problems, identify the key, and then employ the thinking logic of TRIZ before taking appropriate solutions. The improvement and design of this research have helped the feasibility of problem solving, from problem thinking to the process of solving problems, through the use of a design process method and logical thinking concept provided by TRIZ.

This research makes the following contributions with the use of TRIZ.

- From a literatue review, TRIZ is a set of systematic theories with strong logical thinking, which allow people who have not heard of TRIZ to quickly understand its theory and apply it to situations.

- The 39x39 Contradiction Matrix and 40 Invention Principle used in this research are methods for finding a breakthrough solution to problems through TRIZ theory, helping readers to understand the flow model that can apply these methods to solve things.

- A lot of logical thinking is provided in the improved case, which can be applied to other design improvements through logical thinking.

- The new hexagonal socket designed herein under the concept of renovation and innovation can smoothly reduce the problems from sockets rolling around after falling on the ground

\section{REFERENCES}

[1] Chang, C. P., Lin, Y.H. and Lu, C. Y., ” Applying TRIZ Systematic Innovation Method to Improve Urinals”, Advances in Engineering Research, Vols. 22, pp 793-795, 2015.
[2] Chang, C. P., Lin, Y.H.,” Innovative Structure Improvement of A Glare Shield”, Applied Mechanics and Materials, Vols. 321-324, pp 42-45, 2013.

[3] Dana W. and Clarke, Sr. "40 Principles Extended Edition: TRIZ Keys to Technical Innovation”, Technical innovation center, pp.11-13, 2005.

[4] Dana W. and Clarke, Sr., "40 Principles Extended Edition: TRIZ Keys to Technical Innovation”, Technical innovation center, pp.17-18, 2005.

[5] M.H. Sung, Systematic innovation : An introduction to TRIZ, Tingmao Publish Co., 2009.

[6] T. L. Chiang, Theory of Inventive Problem Solving, pp.40-48 Yuhe Publish Co., 2008 